\title{
SOROPREVALÊNCIA E FATORES DE RISCO PARA A INFECÇÃO PELO VÍRUS DA HEPATITE B PELOS MARCADORES AgHBS E ANTI-HBS EM PRISIONEIROS E PRIMODOADORES DE SANGUE*
}

\author{
Celina Maria Turchi Martelli** \\ Ana Lúcia Sampaio Sgambatti de Andrade** \\ Divina das Dores Paula Cardoso*** \\ Luiz Carlos Silva Sousa**** \\ Simonne Almeida e Silva***** \\ Marta Antunes de Sousa ${ }^{* * * * *}$ \\ Fábio Zicker**
}

\begin{abstract}
MARTELLI, C. M. T. et al. Soroprevalência e fatores de risco para a infecção pelo vírus da hepatite B pelos marcadores AgHBs e anti-HBs em prisioneiros e primodoadores de sangue. Rev. Saúde públ., $S$. Paulo, 24: 270-6, 1990.
\end{abstract}

RESUMO: Foram rastreados 1.033 primodoadores de sangue e 201 prisioneiros, para a infecção pelo vírus da hepatite B (VHB), durante o período de junho de 1988 a fevereiro de 1989 , em Goiânia, GO (Brasil). Foi estimada a soroprevalência dos marcadores AgHBs e anti-HBs, e estudados os fatores de risco associados a soropositividade. Os testes sorológicos foram realizados pela técnica de ELISA e a presença de qualquer dos marcadores estudados foi interpretada como exposição ao vírus da hepatite B. Um questionário padronizado foi aplicado em ambos os grupos populacionais para avaliar: transfusão sangúínea prévia, número de parceiros sexuais, atividade homo/bissexual, história de outras doenças sexualmente transmissíveis, uso de droga injetável, uso de medicação injetável, acupuntura, tatuagem e soropositividade ao VDRL. Foram obtidas soroprevalências globais para a infecção pelo VHB de $26,4 \%$ e $12,8 \%$ para a população carcerária e de primodoadores respectivamente, diferença estatisticamente significante $(p<0,05)$, observando-se tendência crescente da soropositividade com a idade $\left(X^{2}\right.$ para tendência $=14,0$, $\mathrm{p}<0,05)$. A população carcerária apresentou maiores percentuais de exposição a todos os fatores de risco quando comparada aos primodoadores, a exceção do número de parceiros sexuais. Grupo etário, encarceramento e presença de tatuagem foram os fatores de risco estatisticamente significantes associados a soropositividade, mesmo após análise multivariada controlada por idade e encarceramento. Foram discutidas as dificuldades metodológicas que poderiam ter influenciado nos resultados.

DESCRITORES: Hepatite B, diagnóstico. Sorodiagnóstico. Fatores de risco. Doadores de sangue. Prisioneiros.

\section{INTRODUÇÃO}

A prevalência da infecção pelo vírus da hepatite $B(V H B)$ na população tem sido estimada através da notificação de casos pelos sistemas oficiais de vigilância epidemiológica, pelo rastreamento sorológico realizado nos bancos de sangue ou, eventualmente, em inquéritos epidemiológicos regionais com finalidade de pesquisa ${ }^{20,27,28,39}$.

Entretanto, mesmo nos países com sistema de vigilância epidemiológica eficiente, onde a hepatite $B$ é de notificação compulsória, estima-se um grande volume de subnotificação de casos, explica- do, em parte, pela associação entre esta infecção e grupos socialmente marginalizados, como usuários de drogas e homossexuais ${ }^{3}$. Por outro lado, o rastreamento sorológico realizado nos bancos de sangue tem-se constituído em uma fonte rotineira de informações epidemiológicas para a estimativa da prevalência da hepatite $B$, mesmo aceitando que os doadores de sangue constituam um grupo selecionado do ponto de vista de morbidade ${ }^{4}$.

Estudos epidemiológicos têm identificado como fatores de risco à infecção pelo VHB, práticas sexuais com múltiplos parceiros (homo e heterossexuais) ${ }^{2,18,33,36}$, uso de drogas endovenosas ${ }^{8}$, hemo-

\footnotetext{
* Trabalho financiado pelo Conselho Nacional de Desenvolvimento Científico e Tecnológico - CNPq (Processo 404230/88-1) e Secretaria de Ciência e Tecnologia do Ministério da Saúde (Convênio 001/89 MS/UFG).

* Departamento de Saúde Coletiva do Instituto de Patologia Tropical e Saúde Pública da Universidade Federal de Goiás. Praça Universitária, s/n - Setor Universitário - 74000 - Goiânia, GO - Brasil.

* * Departamento de Microbiologia do Instituto de Patologia Tropical e Saúde Pública da Universidade Federal de Goiás.

*** Hospital de Doenças Tropicais de Goiânia/(SUDS) - Estrada Velha de Bela Vista, s/n, Setor Bela Vista 74000 - Goiânia, GO - Brasil.

**** Bolsista de Conselho Nacional de Desenvolvimento Científico e Tecnológico - CNPq.
} 
diálise e transfusões sanguíneas ${ }^{26,35,38}$, instituições para deficientes mentais ${ }^{13,24}$, encarceramento ${ }^{22} \mathrm{e}$ atividades profissionais relacionadas com sangue e hemoderivados ${ }^{12,32}$, entre outros.

No Brasil, vários inquéritos sorológicos têm sido realizados no intuito de identificar grupos potencialmente em risco para infecção pelo VHB, constituindo-se em informaçōes básicas para as estratégias de prevenção da hepatite $\mathrm{B}^{1,5,15,16,25,29,30,34 \text {. }}$

Desta forma, os estudos de prevalência indicam que a população de presidiários constituiria um grupo de alto risco para hepatite $B$, enquanto os doadores de sangue seriam considerados de baixo risco apresentando as menores taxas de prevalên$\mathrm{cia}^{7}$. Presume-se que a prevalência esperada para a população em geral estaria situada entre estes limites. Entretanto, poucos estudos epidemiológicos têm investigado os fatores de risco associados a soropositividade em nosso meio.

O presente estudo objetiva comparar a freqüência de fatores de risco para a infecção pélo VHB em população de doadores de sangue e em presidiários, bem como estimar a associação destes fatores com a positividade aos marcadores sorológicos da infecção, HBsAg e anti-HBsAg.

\section{MATERIAL E MÉTODO}

O estudo foi realizado no período de junho de 1988 a fevereiro de 1989, na cidade de Goiânia$\mathrm{GO}$, pela análise seccional, rastreando duas populações distintas: primodoadores de sangue e população carcerária, consideradas, respectivamente, de baixo e alto risco para a infecção pelo vírus da hepatite $B$.

O estudo foi submetido à apreciação, nos seus aspectos éticos, das Secretarias de Justiça e Saúde e do Conselho Coordenador de Ensino e Pesquisa da Universidade Federal de Goiás.

\section{Primodoadores de Sangue}

Os doadores de sangue foram selecionados nos 5 principais bancos de sangue da cidade, do total dos 8 existentes, os quais representam cerca de $90 \%$ das doações de sangue do município. Todas as doações foram voluntárias, não remuneradas, sendo considerados como primodoadores os indivíduos que se apresentaram como candidatos à doação de sangue pela primeira vez. Doadores habituais foram excluídos do estudo no intuito de se evitar distorções na estimativa de prevalência, uma vez que estes individuos já haviam se submetido a rastreamento sorológico anteriormente, constituindo-se, portanto, uma amostra pré-selecionada. Foram também excluídos militares ou indivíduos encaminhados por empresas, devido à dificuldade de se estabelecer a espontaneidade dessas doações.
Considerando-se que as clientelas de doadores de diferentes bancos de sangue não apresentavam diferenças sócio-demográficas importantes, a amostra foi selecionada sem estratificação. Foram incluídos 1.033 primodoadores, correspondendo a $50 \%$ da demanda dos bancos de sangue durante o período de coleta dos dados. Esta amostra foi considerada suficiente para estimar uma prevalência esperada de $0,9 \%$ para o marcador AgHBs com margem de erro de $2 \%{ }^{4}$.

\section{População de Presidiários}

Foram estudados 201 prisioneiros do total de 299 presentes em julho de 1988, no único presídio do Estado de Goiás, Centro Penitenciário de Atividades Agroindustriais de Goiás (CEPAIGO), localizado a $20 \mathrm{~km}$ de Goiânia. Esses indivíduos foram selecionados aleatoriamente, sendo todos do sexo masculino, e procedentes em sua maioria do interior do Estado de Goiás. Apenas dois detentos recusaram-se a participar do estudo, alegando receio da coleta de sangue.

\section{Coleta de dados}

As informações sobre fatores de risco associados a infecção pelo VHB foram obtidas por meio de entrevista utilizando-se um questionário padronizado aplicado por um único entrevistador para cada instituição. Os entrevistadores foram treinados num estudo piloto visando a minimizar os vieses inter-entrevistadores e aperfeiçoar o questionário. Foram avaliados como fatores de risco para a infecção pelo VHB: antecedentes de transfusão de sangue, uso de drogas injetáveis, uso de medicação injetável, antecedente de outras doenças sexualmente transmissiveis (sífilis, gonorréia, herpes genital, condiloma, linfogranuloma e cancróide) codificada em número de episódios, presença de tatuagem, positividade ao VDRL (qualquer titulação), e número de parceiros sexuais (homens, mulheres e travestis) no último ano.

\section{Testes Sorológicos}

No momento da entrevista foram coletados 10 $\mathrm{ml}$ de sangue para os testes de detecção do AgHBs e anti-HBs, realizados pela técnica de ELISA (Voller-1978) ${ }^{37}$, no Laboratório de Virologia do Departamento de Microbiologia do Instituto de Patologia Tropical e Saúde Pública-UFG. A preparação e avaliação dos reagentes biológicos foram realizadas de acordo com a técnica de Camargo e col. (1987)6, e os reagentes cedidos pelo Centro de Referência Nacional para Hepatites Virais da Fundação Oswaldo Cruz (FIOCRUZ). A leitura dos resultados foi visual por comparação com os controles positivos e negativos.

A positividade a qualquer um dos marcadores estudados foi interpretada como exposição ao vírus da hepatite B. Estima-se que a não utili- 
zaçāo do marcador anti-HBc pode ter subestimado a soropositividade em $3 \%-5 \% 14,21$. Em nosso meio, a hipótese da positividade ao marcador anti-HBs ser decorrente de vacinação prévia contra hepatite $B$ parece pouco provável, principalmente em população de doadores de sangue e prisioneiros, devido ao alto custo desta vacina, indicação restrita a grupos de alto risco e a não utilização em campanhas de saúde pública.

Para a reação de VDRL (Venereal Disease Research Laboratories Tests) foram utilizados "kits" Laborclin. As amostras de sangue dos primodoadores foram testadas pelo rastreamento rotineiro nos respectivos bancos de sangue e as dos presidiários foram testadas em um único banco de sangue (Hemocentro). Foram considerados como testes positivos para efeito de rastreamento todos os resultados reagentes ao VDRL, independentemente do título.

\section{Análise}

Os dados da entrevista e os resultados sorológicos foram digitados em microcomputador e analisados através do programa "Statistical Package for Social Science" (SPSS Inc., 1988).

Foram comparadas as taxas de soroprevalência por faixa etária e a freqüência dos fatores de risco nas populações estudadas. Foi estimado o risco relativo "odds ratio" de soropositividade associado às variáveis investigadas em análises univariadas. Os fatores que apresentaram associação estatisticamente significante com soropositividade foram testados pelas análises multivariadas por regressão logística, utilizando o programa "Epidemiological Graphics, Estimation and Testing Package-EGRET" (Statistics and Epidemiology Research Corporation, 1988). Idade e encarceramento foram os principais fatores confundidores controlados.

Foi utilizado o teste de qui-quadrado para testar a significância de diferenças entre proporções e o qui-quadrado para tendência, para avaliar a relação nível de exposição e soropositividade para variáveis não dicotômicas.

\section{RESULTADOS}

A média de idade das populaçōes de primodoadores e prisioneiros foi de $28(+/-9)$ anos e de 32 $(+/-9)$ anos, respectivamente (Teste $t$ estatisticamente significante). $\mathrm{Na}$ faixa etária de 18 a 39 anos estavam $70 \%$ dos participantes.

A prevalência de AgHBs e anti-HBs foi de $2,1 \%$ e $24,3 \%$ para os prisioneiros e de $1,9 \%$ e $10,9 \%$ para primodoadores. Foram obtidas soroprevalências globais para infecção ( $\mathrm{AgHBs}$ ou anti-HBs) de $26,4 \%$ e $12,8 \%$ para população carcerária e de primodoadores, respectivamente, di- ferença estatisticamente significante $(p<0,05)$.

Verificou-se aumento de prevalência com a idade, variando de $11,8 \%$ a $20,3 \%$ para ambas as

\section{TABELA 1}

Prevalência dos marcadores sorológicos da infecção pelo VHB, (AgHBs ou anti-HBs) por faixa etária em prisioneiros e em primodoadores de sangue, Goiânia, 1988-1989

\begin{tabular}{lccc}
\hline $\begin{array}{l}\text { Faixa } \\
\text { etária }\end{array}$ & $\begin{array}{c}\text { Prisioneiros } \\
\text { pos/n(\%) }\end{array}$ & $\begin{array}{c}\text { Primodoadores } \\
\text { pos/n(\%) }\end{array}$ & $\begin{array}{c}\text { Total } \\
\text { pos/n(\%) }\end{array}$ \\
\hline$<=29$ anos & $20 / 95(21,0)$ & $72 / 686(10,5)$ & $92 / 780(11,8)$ \\
$30-39$ anos & $27 / 72(37,5)$ & $36 / 232(15,5)$ & $63 / 304(20,7)$ \\
$>=40$ anos & $6 / 34(17,6)$ & $24 / 114(21,0)$ & $30 / 148(20,3)$ \\
\hline Total & $53 / 201(26,4) *$ & $132 / 1032^{*} *(12,8) *$ & $185 / 1232$ \\
$(15,0 \% * *$ & & & \\
\hline
\end{tabular}

pos $/ \mathrm{n}=$ número de indivíduos com resultado positivo/total de indivíduos na faixa etária

- soroprevalência prisioneiros vs. primodoadores, $\mathrm{p}<0,05$

* 01 primodoador sem registro de idade.

*** soroprevalência por faixa etária, $X^{2}$ para tendência, $\mathrm{p}<0,05$.

\section{TABELA 2}

Freqüuencia de fatores de risco para a infecção pelo VHB em prisioneiros e em primodoadores, Goiânia, 1988-1989

\begin{tabular}{|c|c|c|}
\hline $\begin{array}{l}\text { Fatores de } \\
\text { Risco }\end{array}$ & $\begin{array}{c}\text { Prisioneiros } \\
(\%)\end{array}$ & $\begin{array}{c}\text { Primodoadores } \\
(\%)\end{array}$ \\
\hline $\begin{array}{l}\text { Antecedentes } \\
\text { transfusão } \\
\text { sangüínea }\end{array}$ & 10,9 & $3,4^{* *}$ \\
\hline $\begin{array}{l}\text { Uso de } \\
\text { medicação } \\
\text { injetável }\end{array}$ & 93,4 & $66,1^{* *}$ \\
\hline $\begin{array}{l}\text { Uso de } \\
\text { droga } \\
\text { injetável }\end{array}$ & 14,4 & $1,0^{* *}$ \\
\hline $\begin{array}{l}\text { Presença de } \\
\text { tatuagem }\end{array}$ & 15,9 & $5,9^{* *}$ \\
\hline $\begin{array}{l}\text { Número de } \\
\text { parceiras } \\
\text { sexuais } \geq 5\end{array}$ & 8,5 & $13,6^{*}$ \\
\hline $\begin{array}{l}\text { Positividade } \\
\text { ao VDRL }\end{array}$ & 20,4 & $1,8^{* *}$ \\
\hline $\begin{array}{l}\text { Antecedentes } \\
\text { de DST }\end{array}$ & 63,7 & $31,8^{* *}$ \\
\hline $\begin{array}{l}\text { Homossexualismo } \\
\text { bissexualismo }\end{array}$ & 3,5 & $1,1^{*}$ \\
\hline
\end{tabular}


populações, configurando uma tendência crescente da soropositividade com a idade ( $x^{2}$ para tendência $=14,0$ p<0,05) $($ Tabela 1$)$.

A população carcerária apresentou maiores percentuais de exposição a todos fatores de risco investigados, em relação a população de primodoadores, a exceção do número de parceiras sexuais (Tabela 2).

\section{TABELA 3}

Fatores de risco associados a infecção pelo VHB em população de prisioneiros e de primodoadores de sangue, Goiânia, 1988-1989

\begin{tabular}{|c|c|c|c|c|c|}
\hline & & Infecção & lo $\mathrm{VHB}^{*}$ & - Risco & \\
\hline Fatores de ris & & $\operatorname{sim}$ & não & relativo & $\mathrm{LC}^{* *} 95 \%$ \\
\hline Cárcere & $\begin{array}{l}\text { sim } \\
\text { กão }\end{array}$ & $\begin{array}{r}53 \\
133\end{array}$ & $\begin{array}{l}148 \\
900\end{array}$ & $2,4^{* * *}$ & $(1,7-3,5)$ \\
\hline $\begin{array}{l}\text { História de } \\
\text { transfusão } \\
\text { sangüínea }\end{array}$ & $\begin{array}{l}\text { sim } \\
\text { กão }\end{array}$ & $\begin{array}{r}9 \\
174\end{array}$ & $\begin{array}{l}47 \\
984\end{array}$ & 1,1 & $(0,5-2,3)$ \\
\hline $\begin{array}{l}\text { Uso de } \\
\text { medicação } \\
\text { injetável }\end{array}$ & $\begin{array}{l}\text { sim } \\
\text { não }\end{array}$ & $\begin{array}{r}139 \\
46\end{array}$ & $\begin{array}{l}728 \\
317\end{array}$ & 1,3 & $(0,9-1,9)$ \\
\hline $\begin{array}{l}\text { Uso de droga } \\
\text { injetável }\end{array}$ & $\begin{array}{l}\text { sim } \\
\text { não }\end{array}$ & $\begin{array}{r}8 \\
178\end{array}$ & $\begin{array}{l}31 \\
1016\end{array}$ & 1,5 & $(0,6-3,4)$ \\
\hline $\begin{array}{l}\text { Presença de } \\
\text { tatuagem }\end{array}$ & $\operatorname{sim}_{\text {não }}$ & $\begin{array}{r}26 \\
159\end{array}$ & $\begin{array}{l}67 \\
980\end{array}$ & $2,4^{* * *}$ & $(1,4-4,0)$ \\
\hline $\begin{array}{l}\text { História de } \\
\text { acupuntura }\end{array}$ & $\operatorname{sim}_{\text {não }}$ & $\begin{array}{r}2 \\
183\end{array}$ & $\begin{array}{l}10 \\
1037\end{array}$ & 1,1 & $(0,2-5,2)$ \\
\hline Homo/bissex & $\begin{array}{l}\text { sim } \\
\text { não }\end{array}$ & $\begin{array}{r}3 \\
118\end{array}$ & $\begin{array}{l}14 \\
767\end{array}$ & 1,4 & (inexato) \\
\hline $\begin{array}{l}\text { Positividade } \\
\text { ao VDRL }\end{array}$ & $\begin{array}{l}\text { sim } \\
\text { não }\end{array}$ & $\begin{array}{r}16 \\
170\end{array}$ & $\begin{array}{l}44 \\
1004\end{array}$ & $2,1^{* * * *}$ & $(1,1-4,0)$ \\
\hline $\begin{array}{l}\text { História } \\
\text { de DST }\end{array}$ & $\begin{array}{l}\text { sim } \\
\text { não }\end{array}$ & $\begin{array}{l}88 \\
98\end{array}$ & $\begin{array}{l}368 \\
680\end{array}$ & $1,7^{* * * *}$ & $(1,2-2,3)$ \\
\hline
\end{tabular}

\footnotetext{
* teste positivo para AgHBs ou anti-HBs

* limites de confiança

$* * * \quad p<0,01$

**** $\mathrm{p}<0,05$
}

A Tabela 3 apresenta o risco relativo e limites de confiança de $95 \%$ para a associação entre os fatores de risco avaliados e a infecção pelo VHB. Encarceramento, presença de tatuagem, positividade ao VDRL e episódios de DST foram os fatores de risco estatisticamente significantes associados à soropositividade aos marcadores. No entanto, após análise multivariada controlada por grupo etário e encarceramento, apenas a tatuagem persistiu estatisticamente associada à infecção. Indivíduos tatuados apresentaram risco de 2,3 (L.C.
$95 \%$ 1, 3-3,7) de terem sido infectados pelo VHB que os indivíduos não tatuados. Um risco relativo de 1,5 (L.C. $95 \% 1,1-1,8$ ) e de 1,8 (L.C. 95\% 1, 2-2, 7), $p<0,01$, para soropositividade, foi obtido para idade e encarceramento, respectivamente, após ajustar para presença de tatuagem.

\section{DISCUSSÃO}

A prevenção de infecção pelo $V H B$ vem sendo equacionada pelo reastreamento sorológico realizado sistematicamente pelos bancos de sangue, e/ou pela imunização de grupos de maior risco para infecção. Mesmo assim, a transmissão sexual e através do uso de droga injetável persistem como problemas de saúde pública de difícil intervenção.

Com a recente epidemia de infecção pelo vírus da Imunodeficiência Humana (HIV), as investigações epidemiológicas sobre a dinâmica de transmissão da infecção pelo VHB ganharam novo impulso, não só pela similaridade dos mecanismos de transmissão mas também dos grupos mais acometidos em ambas infecções $9,17,19$.

Ao contrário da maioria das Doenças Sexualmente Transmissíveis, na infecção pelo VHB, é possível a obtenção de perfis sorológicos diversos, com marcadores duradouros, que permitem estabelecer o grau de exposição prévia ao VHB e avaliar diferenciais de risco entre populações.

No presente estudo a população carcerária apresentou elevadas taxas de soroprevalência $(26,4 \%)$ para AgHBs ou anti-HBs, duas vezes maior que a obtida nos primodoadores de sangue. Houve tendência de aumento da prevalência de anticorpos com a idade, também descrita em outros estudos populacionais ${ }^{1,25}$.

Embora indivíduos submetidos a reclusão sejam considerados genericamente um grupo potencialmente de risco para infecção pelo VHB, as diferenças na procedência (urbano/rural), composição etária e de risco (\% de usuários de drogas, $\%$ de homossexualismo) dos prisioneiros e particularmente das condições de cárcere (aglomeração, período de permanência) reforçam as especificidades regionais de cada estudo.

Inquéritos sorológicos realizados em prisioneiros, no Brasil, têm encontrado taxas de exposição de até $60 \%$ (5,4\% para AgHBs e $54,6 \%$ para antiHBs), enquanto taxas de $29,9 \%$ foram obtidas em estudos norte-americanos 7,10 .

As variações de prevalências obtidas, entre diferentes regiōes do país são difíceis de serem analisadas devido a diferenças entre testes laboratoriais empregados, e ainda por não se dispor, na maioria das vezes, de informações sobre idade, características de exposição ao VHB, além de problemas relativos a representatividade da amostra. 
Considerando-se a especifidade de cada grupo populacional duas hipóteses, não excludentes, poderiam explicar as altas taxas de prevalência encontradas em prisioneiros:

1. Esses indivíduos poderiam já pertencer previamente a algum grupo de risco no momento da admissão no presídio, o que representaria uma amostra tendenciosa, pré-selecionada, da população em geral.

2. O encarceramento poderia ser o fator condicionante de risco para infeç̧ão nesse grupo, uma vez que as condições de cárcere poderiam levar a mudanças comportamentais que alterariam o risco de infecção.

No presente estudo a população de prisioneiros apresentou maiores percentuais de exposição a todos os fatores de risco investigados, quando comparados aos primodoadores de sangue. Também o encarceramento foi confirmado como fator de risco, estatisticamente associado à infeç̧̃ão, quando se analisou as populaçōes de doadores de sangue e de presidiários em conjunto.

Estes resultados sugerem que as pessoas que compõem a população de prisioneiros parecem ter estilos de vida fora da prisão que as colocam como grupo de risco para a infecção pelo VHB. Além disso, o encarceramento poderia representar um risco adicional, ou poderia sinalizar o grupo mais exposto à infecção pelo VHB. Embora o número de anos de reclusão em relação a soropositividade permita avaliar um gradiente de exposição, esta medida de duração da exposição foi dificultada por períodos de fuga e/ou readmissões.

Em estudo multicentro realizado em prisões nos EUA, além da idade e do encarceramento, o uso de droga injetável foi identificado como importante fator de risco associado ao VHB, diferentemente do homossexualismo que não se confirmou como fator de risco após o controle das variáveis confundidoras ${ }^{11}$.

As dificuldades de obtenção de respostas confiáveis em relação a práticas homossexuais e uso de drogas injetáveis ou o pequeno tamanho da amostra carcerária estudada, podem ter interferido na detecção de uma associação positiva desses fatores no presente estudo. Por outro lado, $16 \%$ da população de prisioneiros apresentava-se tatuada, sendo esta característica estatisticamente mais freqüente nos indivíduos soropositivos, em concordância com outros estudos ${ }^{23}$.

Embora os estudos de prevalência sejam úteis para detectar grupos potencialmente em risco, o conhecimento temporal da relação entre exposição/infecção fica prejudicado, uma vez que nesses estudos essas variáveis são medidas de forma simultânea ${ }^{31}$.

Desta forma, os fatores de risco para infecção para o VHB em população carcerária seriam melhor investigados por meio de estudos prospectivos, de incidência, realizados no momento da admissão. Esses estudos permitiriam comparar coeficientes de incidência e graus de exposição para infecção pelo VHB entre prisioneiros e a população em geral, estabelecendo diferenciais de risco entre essas populaçōes.

MARTELLI, C. M. T. et al. [Seroprevalence and risk factors for hepatitis B by AgHBs and anti-HBs markers in prisoners and first-time donors, in Central Brazil]. Rev. Saúde públ., Såo Paulo, $24: 270-6,1990$.

ABSTRACT: Two cross-sectional surveys on hepatitis B virus (HBV) infection were carried out among 1,033 volunteer first-time blood donors in five blood banks ( 3 private, 2 public) and among 201 prisoners in the Penitentiary Center of Industrial Activity, in Goiania, Central Brazil, between June 1988 and February 1989. Those surveys were part of a major study designed to estimate seroprevalence of HBsAg and anti-HBsAg markers by ELISA test, and to study risk factors associated with seropositivity. The presence of any serum marker was considered as previous exposure to HBV. A standard questionnaire was applied to both populations to evaluate previous blood transfusion, number of sexual partners, homo/bisexual activity, history of sexually transmitted diseases, drug abusers, use of parenteral medicine, accupunture, tattooing and VDRL seropositivity. Seroprevalence varied from $12.8 \%$ to $26.4 \%$ in blood donors and prisoners, respectively, $(p<0.05)$ and increased with age $\left(X^{2}\right.$ trend $\left.=14.0 p<0.05 \%\right)$. Prisoners had higher percentages of all risk factors investigated than blood donors, with the exception of number of sexual partners. Among all risk factors studied, age, imprisonment and tattooing were statistically associated with seropositivity, even after multivariate analysis controlling for age and reclusion. The paper discusses the methodologic issues related to this epidemiologic investigation.

KEYWORDS: Hepatitis B, diagnosis. Serodiagnosis. Risk factors. Blood donors. Prisoners. 


\section{REFERÊNCIAS BIBLIOGRÁFICAS}

1. ABUZWAIDA, A. R. N. ; SIDONI, M.; YOSHIDA, C. F. T.; SCHATZMAYR, H. G. Seroepidemiology of hepatitis $B$ in two urban communities of Rio de Janeiro, Brazil. Reo. Inst. Med. trop. S. Paulo, 29: 219-33, 1987.

2. ALTER, M. J.; AHTONE, J.; WEISFUSE, I.; STARKO, K.; VACALIS, T. D.; MAYNARD, J. E. Hepatitis $B$ virus transmission between heterosexuals. J. Amer. med. Ass. 256: 1307-10, 1986.

3. ALTER, M. J.; MARES, A.; HADLER, S. C.; MAYNARD, J. E. The effect of underreporting on the apparent incidence and epidemiology of acute viral hepatitis. Amer. J. Epidem., 125: 1339, 1987.

4. ANDRADE, A. L. S. S.; MARTELLI, C. M. T.; PINHEIRO, E. D.; SANTANA, C. L.; BORGES, F. P.; ZICKER, F. Rastreamento sorológico para doenças infecciosas em banco de sangue como indicador de morbidade populacional. Rev. Saúde públ., S. Paulo, 23: 20-5, 1989.

5. BENSABATH, G.; HADLER, S. C.; SOARES, M. C. P.; FIELDS, H.; MAYNARD, J. Caracteristicas serologicas y epidemiologicas de la hepatitis virica aguda. Bol. Ofic. sanit. panamer. 103: 351-62, 1987.

6. CAMARGO, I. F,; GASPAR, A. M. C.; YOSHIDA, C. F. T. Comparative Elisa Reagents for Detection of Hepatitis B Surface Antigen (HBsAg). Mem. Inst. Oswaldo Cruz, 82: 181-7, 1987.

7. CARRILHO, F. J. \& SILVA, L. C. Epidemiologia. In: Silva, L. C., ed. Hepatites agudas e crônicas. São Paulo, Ed. Sarvier, 1986.p. 47-69.

8. CENTERS FOR DISEASE CONTROL, Atlanta, Ga. Changing patterns of groups at hight risk for hepatitis B in The United States. Morb. Mort. wkly Rep., 37:429-37, 1988.

9. COCK, K. M.; NILAND J. C.; LU, H. P.; RAHIMIAN A.; EDWARDS, V.; SHIVER, K.; GOVINDARAJAN, S.; REDEKER, A. G. Experience with human immunodeficiency virus infection in patients with hepatitis B virus infections in Los Angeles, 19771985. Amer. J. Epidem, 127:1250-60, 1988.

10. DECKER, M. D.; VAUGHN, W. K.; BRODIE, J. S.; HUTCHESON, R. H.; SCHAFFNER, W. Seroepidemiology of Hepatitis B in Tenessee Prisoners. J. infect. Dis., 150: 450-9, 1984.

11. DECKER, M. D,; VAUGH, W. K.; BRODIE, J. S.; HUTCHESON, R. H.; SCHAFFNER, W. The incidence of hepatitis $B$ in Tenessee prisoners. J. infect. Dis. 152: 214-7, 1985.

12. DIENSTAG, J. L. \& RYAN, D. M. Occupational exposure to hepatitis B virus in hospital personnel: infection or immunization? Amer. J. Epidem., 115: 26-39, 1982.

13. DITZHUIJSEN, Th. J. M. Van; WITTE - van der SCHOOT, E. ; LOON, A. M. van; RIJNTJES, P. J.
M.; YAP, S. H. Hepatitis B virus infection in an institution for the mentally retarded. Amer. J. Epidem., 128: 629-38, 1988.

14. EDWARDS, M. S. Hepatitis B serology help in interpretation. Pediat. clin. North Amer., 35: 50315, 1988.

15. FIGUEIREDO, J. F. C.; MOYSES-NETO, M.; GOMES, U. A.; FERRAZ, A. S.; BATISTA, M. E. P. N.; GASPAR, A. M. C.; YOSHIDA, C. F. T. Hepatitis $B$ virus infection in hemodialysis units: clinical features, epidemiological markers and general control, measures. Braz. J. med. Biol. Res., 19: 735$42,1986$.

16. FONSECA, J. C. F.; SIMONETTI, S. R. R.; SCHATZMAYR, H. G.; CASTEJON, M. J.; CESARIO, A. L. O.; SIMONETTI, J. P. Prevalence of infection with hepatitis B surface antigen in Amazonas State, Brazil. Trans. roy. Soc. trop. Med., 82: 469-71, 1988.

17. GARIBALDI, R. A. Transmission of hepatitis B and AIDS. Infect. Control, 7 (Suppl. ): 132-4, 1986.

18. GOH, C. L.; RAJAN, V. S.; CHAN, S. H.; KAMARUDIN, A. Hepatitis B infection in prostitutes. Int. J. Epidem.; 15: 112-5, 1986.

19. HADLER, S. C. Hepatitis B prevention and Human Immunodeficiency Virus (HIV) infection. Ann. intern. Med., 109: 92-4, 1988.

20. HADLER, S. C.; FAY, O. H.; PINHEIRO, F.; MAYNARD, J. E. La hepatitis en las Americas: informe del grupo colaborador de la OPS. Bol. Ofic. sanit. panamer., 103: 185-208, 1987.

21. HOOFNAGLE, J. H. Serologic markers of hepatitis B virus infection. Ann. Reo. Med., 32: 1-11, 1981.

22. KOPLAN, J. P.; WALKER, J. A.; BRYAN, J. A. Prevalence of hepatitis B surface antigen and antibody at a state prison in Kansas. J. infect. Dis., 137: 505-6, 1978.

23. LIMENTANI, A. E.; ELLIOTT, L. M.; NOAH, N. D.; LAMBORN, J. K. An outbreak of hepatitis B from tattooing. Lancet, 2: 86-8, 1979.

24. LOHITA, S.; LOHITA, G.; CAIRES, S. Epidemiology of hepatitis $B$ infection in institutionalized mentally retarded clients. Amer. J. publ. Hlth, 76: 799-802, 1986

25. LYRA, L. G.; DAMASCENO, A. P.; COTRIM, P.; MOTA, E.; SILVA, L. Prevalence of antibody to hepatitis $B$ virus in an urban population of Northeast Brazil. Rev. Inst. Med. trop. S. Paulo, 28: 406-9, 1986.

26. MAGGIORE, Q. \& CATALANO, C. Viral hepatitis in dialysis units: a changing scenario. Contr. Nephrol., 61: 240-53, 1988.

27. MAZZUR, S.; NATH, N.; FANG, C.; BASTIAANS, M. J.; MOLINARIS, J. L.; BALCASER, M.; BEKER, G. S.; BRUNINGS, E. A.; CAMERON, A. R. E.; FARREL, V.; FAY, O. H.; LABRADOR- 
GONZALES, G.; GUTIERREZ, D. A.; JARAMILLO, T. C.; KATZ, R.; LEME-LOPEZ, M. B.; LEVYKOENING, E.; MORALES AYALA, F.; RODRIGUEZ AMAYA, J.; RODRIGUEZ MOYADO, $\mathrm{H}$.; TORRES, R. A. de.; VELASCO, M; Distribucion de marcadores de virus de Hepatitis $B(V H B)$ en donatores de sangre de 13 paises del hemisferio ocidental: actas del Taller Latinoamericano de Cruz Roja sobre Hepatitis B. Bol. Ofic. sanit. panamer., 89: 239-47, 1980.

28. PASQUINI, P.; KAHN, H. A.; PILEGGI, D.; PANA, A.; TERZI, J.; GUZZANTI, E. Prevalence of Hepatitis B Markers in Italy. Amer. J. Epidem. 118: 699-709, 1983.

29. ROMÃO Jr., J. E. Hepatite B em hemodialise. J. bras. Nefrol., 6(1): 2-3, 1984.

30. ROSA, H.; LEMOS, Z. P.; MAGALHÃES, A. F. N.; CARDOSO, V. M. HAA, imunoglobulinas e autoanticorpos em retardados mentais, doadores de sangue e hepatite viral aguda. In: Congresso Brasileiro de Gastroenterologia, 24², Petrópolis, 1984. Petrópolis, 1984. p.175.

31. ROTHMAN, K. J. Modern epidemiology. Boston, Ed. Little, Brown and Co., 1986.

32. SCHEUTZ, F.; MELBYE, M.; ESTEBAN, J. I.;ALDERSHVILE, J.; EBBESEN, P.; ALTER, H. J. Hepatitis B virus infection in Danish dentists: a case control and follow up study. Amer. J. Epidem., 128: 190-6, 1988.

33. SCHREEDER, M. T.; THOMPSON, S. E.; HADLER, S. C.; BERQUIST, K. R.; ZAIDI, A.; MAYNARD, J. E.; OSTROW, D.; JUDSON, F. N.; BRAFF, E. H.; NYLUND, T.; MOORE Jr, J. N.; GARDNER, P.; DOTO, I. L.; REYNOLDS, G. Hepatitis B in homo- sexual men: prevalence of infection and factor related to transmission. J. infect. Dis., 146: 7-15, 1982.

34. SILVA, L. C. da.; CARRILHO, F. J.; DI PIETRO, A.; BORIS-CHAVES, A.; ALBORNOZ, P.; SETTE Jr, H.; FRANCO, F. F.; ANTONELLI, R.; SAEZALQUEZAR, A. Epidemiological aspects of acute viral hepatitis in São Paulo, Brazil. Reo. Inst. Med. trop. S. Paulo, 28: 400-5, 1986.

35. STROM, T. B. Hepatitis B transfusions, and renal transplantation: five years later. New Engl. J. Med., 307: 1142-43, 1982.

36. SZMUNESS, W.; MUCH, I.; PRINCE, A. M.; HOOFNAGLE, J. H.; CHERUBIN, C. E.; HARLEY, E. J.; BLOCK, G. H. On the role of sexual behavior in the spread of hepatitis B infection. Ann. intern. Med., 83: 489-95, 1975.

37. VOLLER, A.; BARTETT, A.; BIDWEIL D. E. Enzyme immunoassays with special reference to ELISA techniques. J. clin. Path., 31: 507-20, 1978.

38. WARE, A. J.; GORDER , N. L.; GURIAN, L. E.; DOUGLAS, C.; SHOREY, J. W.; PARKER, T. Value of screening for markers of hepatitis in dialysis units. Hepatology, 3: 513-8, 1983.

39. YOSHIDA, C. F. T.; NOGUEIRA, R. M. R.; MERCADANTE, L. A. C.; PINHÃO, A. T.; SCHATZMAYR H. G. Soroepidemiological survey of hepatitis $A$ and $B$ cytomegalovirus and herpes simplex type 2 in prime blood donors from Rio de Janeiro, Brazil. Reo. Microbiol., 18: 5-11, 1987.

Recebido para publicação em 29/9/1989

Reapresentado em 21/3/1990

Aprovado para publicação em 2/4/1990 